\title{
CONFINED FLUIDISED BED POROSITY IN THE LIGHT OF BUBBLING-BED MODELS
}

\author{
Piotr Zabierowski ${ }^{*}$ \\ University of Science and Technology, Faculty of Energy and Fuel, al. Mickiewicza 30, \\ 30-059 Cracow, Poland
}

\begin{abstract}
Based on hydrodynamic data, Kato-Wen and Kunii-Levenspiel bubbling-bed model parameters, supplemented with assumptions characteristic for tested confined fluidised bed, were analysed. The calculated bubble diameters and the bed composition proved essential influence of inter-particle space of packed compacted component onto fluidisation character. The usability of the conducted model analysis was also confirmed. Finally, it can be concluded that Kunii-Levenspiel and KatoWen models with characteristic assumptions (for the tested bed) can be applied for calculation of the confined fluidised bed layer porosity. Discrepancies of $\varepsilon_{f}$ value, determined on the basis of the above mentioned bubbling-bed models do not exceed $8 \%$ of the error. The model parameters obtained from the matching the model relations to experimental data $\varepsilon_{f}=\mathrm{f}\left(u_{0}\right)$ allow an analysis of the fluidisation character as well as gas velocity regime and the fluidised bed structural composition identification. A description of the regime of the process in which confined fluidised bed is characterised with an increase of mass and heat transfer rate is also possible using relation (17) derived in the present study.
\end{abstract}

Keywords: fluidisation, bubbling-bed model, confined fluidised bed, hydrodynamic, bubble diameter

\section{INTRODUCTION}

The present study is aimed at the confined fluidised bed analysis, developed as a conventional fluidised bed modification as a result of introduction of big elements forming packed bed into the apparatus (Donsi et al., 1988; Gabor, 1966). These elements restrict the possibility of gas bubble growth, including disadvantageous slugging and channelling phenomena. Fluidisation of fine particles in the inter-particle spaces of a packed bed is possible, if $d_{f} / D_{p}<0.096-0.414$ (Sutherland et al., 1963). So far, Raschig and Pall rings, Berl saddle, cylinders, big-diameter balls, and others were used as a packed bed (Donsi et al., 1990; Gabor, 1966; Roes and Van Swaaij, 1979). Fluidal phase in macroscale is homogeneous in such a bed (linear distribution along the bed height and his smaller fluctuations, constant concentration of the fluidal phase and porosity, no partition into dense and lean phase (Capes and McIlhinney, 1968; Donsi et al., 1988; Dryden and Shubauer, 1947)). However, fluidal phase in micro scale is inhomogeneous (a part of particles is not in contact with gas, particles rest on the packing, and slugging is sometimes observed (Donsi et al., 1990; Roes and Van Swaaij, 1979; Ziółkowski et al., 1989)). In the confined fluidised bed standstill zones and parallel or counter flow zones were observed (Baskakov and Lummi, 1963; Gabor, 1966). The bed operates within the range from minimum fluidisation velocity $u_{m f}$ (higher than in conventional fluidised bed because of inter-particle friction) to entrainment velocity of fluidised particles $u_{s}\left(\varepsilon_{f}=1\right)$, less than the terminal velocity over packed bed (Capes and McIlhinney, 1968; Michalski and Ziółkowski, 1999).

*Corresponding author, e-mail: zabierow@agh.edu.pl 
Experimental data of the fluidal layer expansion $\varepsilon_{f}=\mathrm{f}\left(u_{0}\right)$ were matched using Richardson-Zaki relation in packing porosity systems $\varepsilon_{p}=0.97$, and in systems where $\varepsilon_{p}=0.45$ as empirical equation (Buczek and Zabierowski, 2001; Capes and McIlhinney, 1968; Donsi et al., 1990). Different relations were also used where particles geometry and the system aerodynamics were taken into consideration (Donsi et al., 1990; Ziółkowski et al., 1989). The similarity of the fluidal phase and incompressible liquid was underlined.

A proper selection of hydrodynamic model and fluidal layer composition is very important. Bubblingbed models, which are commonly used for conventional fluidisation, combine hydrodynamic features with mass and heat exchange characteristics (Wen-Ching, 2003). There is still no answer to the question how the bubbling-bed models describe the confined fluidisation system and conducted attempts have qualitative character and should be supplemented (Gabor, 1966). The present study is aimed at the analysis of the relationship between confined fluidised bed expansion and fluidal structural layer features. The analysis was performed on the basis of main assumptions of three-dimensional Kunii-Levenspiel and Kato-Wen models.

\section{EXPERIMENTAL}

The modelling was conducted on the basis of three data sources presenting the relation between interparticle porosity changes of the fluidal phase $\left(\varepsilon_{f}\right)$ and gas velocity growth $\left(u_{0}\right)$. In all cases the experiments were conducted according to commonly used procedures, where height of the upper limit of fluidal bed in inter-particle spaces and mass of the fluidised materials, were recorded with increasing gas velocity. The experiments were conducted in round-bottom columns with 1/10 diameter to height proportion. The sphere-shaped particles of the diameter at least 10 times smaller than the column diameter and humidified air as the gas were used.

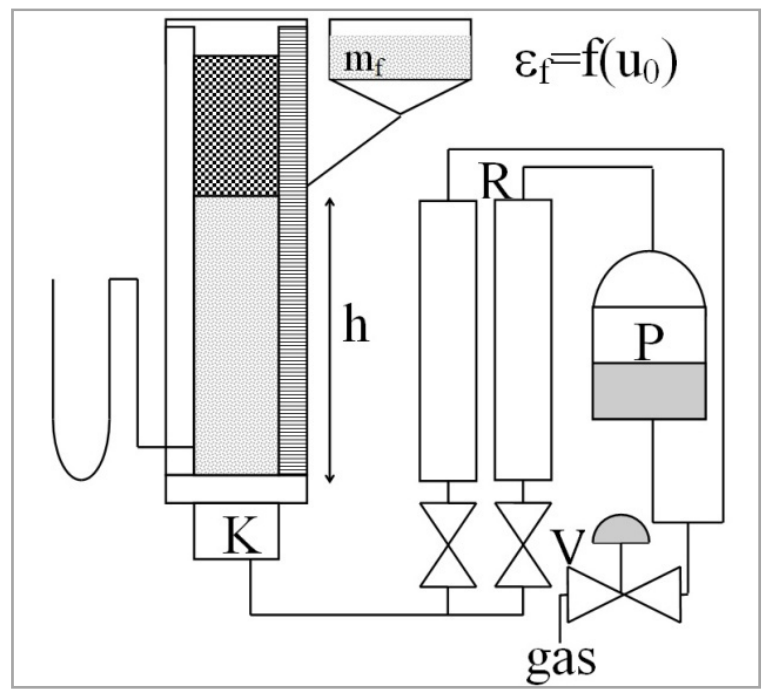

Fig. 1. Experimental equipment. $\mathrm{K}$-column; $\mathrm{R}$ - rotameters; $\mathrm{P}$ - washers; $\mathrm{V}$ - valves

The first source comprised data $\varepsilon_{f}=\mathrm{f}\left(u_{0}\right)$ obtained from the authour's experiments (Fig. 1), conducted with glass fluidal particles with diameters $0.055 \cdot 10^{-3} \mathrm{~m}(\mathrm{~d} 1), 0.088 \cdot 10^{-3} \mathrm{~m}(\mathrm{~d} 2), \quad 0.125 \cdot 10^{-3} \mathrm{~m}(\mathrm{~d} 3)$ (classified respectively to A, B, B Geldart's group) and true density $\varepsilon_{f}=2433 \mathrm{~kg} / \mathrm{m}^{3}$. Three types of big adsorbent particles from Geldart's group D: silica gel (SZ), active aluminium oxide (TG) or molecular sieve $4 \mathrm{~A}(\mathrm{~A} 4)$ of diameter $\left(D_{p}\right)$ and porosity of packed layer $\left(\varepsilon_{p}\right)$, which were equal to $3.6 \cdot 10^{-3} \mathrm{~m}$, $0.44 \mathrm{~m}^{3} / \mathrm{m}^{3} ; 2.2 \cdot 10^{-3} \mathrm{~m}, 0.38 \mathrm{~m}^{3} / \mathrm{m}^{3} ; 3.6 \cdot 10^{-3} \mathrm{~m}, 0.45 \mathrm{~m}^{3} / \mathrm{m}^{3}$, formed the packet bed in the conducted experiments. The same materials were used and described in (Buczek and Zabierowski, 20011 Zabierowski, 2009; Zabierowski, 2008). To estimate $\varepsilon_{f}=\mathrm{f}\left(u_{0}\right)$ relation (where $\varepsilon_{f} \in 0.5-1$ ), five series 
of experiments were conducted (d1-d3/SZ,d3/TG,d3/4A). During the series (experimental data $n=40$ ), fine particles were supplemented to the fluidised bed within the packed bed column $(0.5 \mathrm{~m}$ height), depending on the gas flow rate.

The second data source comprised empirical relations $\varepsilon_{f}=\mathrm{f}\left(u_{0}\right)$ Richardson Zaki type, published in (Donsi et al., 1988; Donsi et al., 1990). The data were studied in chosen, original systems, for which they were formulated. Particles of the fluid phase had a form of glass balls of diameters $0.077 \cdot 10^{-3} \mathrm{~m}$ (d4), $0.108 \cdot 10^{-3} \mathrm{~m}(\mathrm{~d} 5)$, true density $\varepsilon_{f}=2530 \mathrm{~kg} / \mathrm{m}^{3}$, classified to A and B Geldart's group. The packed bed was composed from lead balls of diameters $1.85 \cdot 10^{-3} \mathrm{~m}(\mathrm{D} 1), 3 \cdot 10^{-3} \mathrm{~m}(\mathrm{D} 2), 4 \cdot 10^{-3} \mathrm{~m}$ (D3) and porosity of $0.4 \mathrm{~m}^{3} / \mathrm{m}^{3}$.

The third data source comprised empirical relations $\varepsilon_{\mathrm{f}}=\mathrm{f}\left(\mathrm{u}_{0}\right)$ published in works (Michalski and Ziółkowski, 1999; Ziółkowski et al., 1989), obtained in open and closed confined fluidised bed. The data were studied in chosen, original systems, for which they were formulated. Fluidisation of fine sand particles of diameters: $0.225 \cdot 10^{-3} \mathrm{~m}(\mathrm{~d} 6), 0.275 \cdot 10^{-3} \mathrm{~m}(\mathrm{~d} 7), 0.343 \cdot 10^{-3} \mathrm{~m}(\mathrm{~d} 8)$, true density $\varepsilon_{f}=2640 \mathrm{~kg} / \mathrm{m}^{3}$ from B Geldart's group in packed bed consisting of balls of diameter $\left(D_{p}\right)$ and packed bed density $\left(\varepsilon_{p}\right)$ amounting for: $15 \cdot 10^{-3} \mathrm{~m}, 0.4 \mathrm{~m}^{3} / \mathrm{m}^{3}(\mathrm{D} 4) ; 20 \cdot 10^{-3} \mathrm{~m}, 0.45 \mathrm{~m}^{3} / \mathrm{m}^{3}$ (D5); $25 \cdot 10^{-3} \mathrm{~m}$, $0.45 \mathrm{~m}^{3} / \mathrm{m}^{3}$ (D6), were discussed.

\subsection{The bubbling-bed model assumptions for a confined fluidised bed}

In the confined fluidised bed there is no possibility of bubble growth (inter-particle space in packed bed has limited size) and relation $\varepsilon_{f}=\mathrm{f}\left(u_{0}\right)$ should be a direct consequence of fluidal layer composition. Experimentally confirmed, the semi-homogeneous fluidisation character may result from identical (in each bed points) portions of distinguished in the bubbling-bed model, two basal bed components: gas bubbles $\left(\varepsilon_{b g}\right)$ and emulsion, cloud-wake phases $\left(\varepsilon_{e}, \varepsilon_{c}\right)$.

\subsection{Development of gas bubbles}

According to the author's and the other authors' observations, gas bubbles are developed in the confined fluidised bed within the whole range of gas velocity changes for particles A and B Geldart's classification (Baskakov and Lummi, 1963; Capes and McIlhinney, 1968; Gabor, 1966). For particles Geldart's group B this is a typical feature of conventional fluidisation (Geldart, 1973). However, in case of grains from group A, bubbles are developed at the velocity $1.5 \div 4$ times higher than $u_{m f}$ (at $u_{m b}$ ) (Buczek and Geldart, 1989). In the confined fluidised bed, accelerations of bubble formation result probably from the interaction between fluidised grains and packed bed. In vicinity of $\mathrm{u}_{\mathrm{mf}}$, for small grains, they cause development of stagnation zones (Michalski and Ziółkowski, 1999), as well as growth of velocity in other bed parts, where gas bubbles are observed. Confined fluidised bed can be also considered as a gas distributor (Zabierowski, 2006), thus a new distribution takes place on each layer height (as in the case of porous distributors or cascades of perforated plates (Ciesielczyk, 1992)). Bubble size $d_{b g}$ developed in such considered confined fluidised bed is similar to the diameter of channels between packed particles, already in the velocity range corresponding to $\varepsilon_{f} \approx 0.6$ (according to estimates by the cited method). The volume occupied by resting fine particles (slugging) was not taken into consideration in assessment calculation. Thus the authour's can assume that the bubble size is similar to the inter-particle space in packed bed at the moment of formation within the whole scope of the velocity $u_{0}$. For this reason there are no favorable conditions for bubble growth during their movement along the confined fluidised bed and eventually formed, new bubbles have a similar diameter. Thus the first of the assumptions (Z1), that within confined fluidised bed of spherical particles and the range $\varepsilon_{f} \geq \varepsilon_{m f}$, favorable conditions for bubbling-type fluidisation occur, where diameter of the bubbles is constant and independent on the fluidised bed height and gas velocity $u_{0}$. 
Thus this bed should be a particular case of conventional fluidised bed, in which the Kunii-Levenspiel model simplification about constant bubble diameter (Kunii and Levenspiel, 1991), corresponds to true fluidisation conditions. Assumption Z1 is consistent with Kato-Wen model (Kato and Wen, 1969), if we assume that the height of fluidised layer is equal to the section height and previous section is considered as distributor. Such a case is a counterpart of conventional bed, where assumptions of KatoWen model are satisfied and bubbles are not developed within some height range, because of the apparatus construction or regime of the process.

\subsection{Phase composition of the confined fluidised bed}

Zones of consistent and reverse movement, as well as stagnation zone (Baskakov and Lummi, 1963; Gabor, 1966), were observed in the confined fluidised bed. The same was confirmed by our own observation of hydrodynamic experiments presented in the study. Gas velocity in emulsion $u_{f}=u_{m f} \varepsilon_{m f}$ ( $u_{m f}$ calc. acc. to Donsi et al., 1990) and bubble velocity in emulsion phase $u_{b r}$ (Kunii and Levenspiel, 1991), have been compared, assuming that bubble diameter is equal to the diameter of channels between packed particles. A condition needed for the occurrence of cloud-wake phases $\left(u_{b r}>u_{f}\right)$ was confirmed for all systems tested in the present study. As seen from the analysis of $u_{b r}$, $u_{f}$, the above conditions for confined fluidised bed are satisfied.

The information presented above allowed (according to three-phase bubbling-bed model) to make assumption (Z2), that pseudo-homogeneous fluidised phase in confined fluidised bed is formed, despite gas bubbles, by the emulsion, wakes and clouds phases. The inter-particle space porosity $\varepsilon_{f}$ is then a sum of individual phases porosity with respect to their volume fractions within a space between packed particles. They are equal respectively: bubbles $\varepsilon_{b g} \cdot \delta$, cloud-wakes $\varepsilon_{c} \cdot \delta \vartheta$ and emulsion $\varepsilon_{c} \cdot(1-\delta-\delta \vartheta)$. It was also assumed (Z3), that volume fraction of solid in bubbles can be neglected $\left(\varepsilon_{b g}\right.$ $=1$ ) and the other phases (Z4) have porosity $\varepsilon_{m f}$, as during fluidisation onset $\left(\varepsilon_{e}=\varepsilon_{c}=\varepsilon_{m f}\right)$. The assumptions in question are compatible with those assumed in Kunii-Levenspiel and Kato-Wen models (Kato and Wen, 1969; Kunii and Levenspiel, 1991). With respect to movement of bubbles surrounded with clouds and wakes toward the bed top, it was assumed (Z5) that the size of external diameter of the system is no bigger than the diameter of channels between packed particles.

In this case the voluminal ratio of bubble and cloud-wake phases to bubble phase should not exceed the value determined by Davidson Harrison (Kunii and Levenspiel, 1991).

\section{CALCULATION PROCEDURE}

Empirical relations $\varepsilon_{f}=\mathrm{f}\left(u_{0}\right)$ were used in the present study in order to determine the structural composition of the system. The relations used in bubbling-bed models were also matched to them. Based on relations used in Kato-Wen models (Kato and Wen, 1969):

$$
\begin{gathered}
\frac{h_{f}-h_{m f}}{h_{m f}}=\frac{u_{0}-u_{m f}}{u_{b r}}=\frac{u_{0}-u_{m f}}{0.711 \sqrt{g d_{b g}}} \\
\frac{1-\varepsilon_{f}}{1-\varepsilon_{m f}}=\frac{h_{m f}}{h_{f}}
\end{gathered}
$$

gas bubble diameter was calculated

$$
d_{b g}=\left(\frac{u_{0}-u_{m f}}{2.227} \frac{1-\varepsilon_{f}}{\varepsilon_{f}-\varepsilon_{m f}}\right)^{2}
$$


Value $d_{b g}$ was presented on diagrams within the whole range of porosity changes. Together with calculated values $r$ (according to model and assumption Z5):

$$
r=\left(\frac{d_{b c}}{d_{b g}}\right)^{3}
$$

they allowed to analyse the Kato-Wen model usability for applied systems.

Based on relations used in Kunii-Levenspiel model (Kunii and Levenspiel, 1991):

$$
\begin{gathered}
\delta=\frac{\varepsilon_{f}-\varepsilon_{m f}}{1-\varepsilon_{m f}} \\
\delta=\frac{u_{0}-u_{m f}}{u_{b}-\xi u_{m f}}=\frac{u_{0}-u_{m f}}{a}
\end{gathered}
$$

value of denominator $\boldsymbol{a}$ :

$$
a=\left(u_{0}-u_{m f}\right) \frac{1-\varepsilon_{f}}{\varepsilon_{f}-\varepsilon_{m f}}=u_{b}-\xi u_{m f}
$$

combining experimental gas porosities and gas velocity $u_{0}$, was obtained. Value $\boldsymbol{a}$ dependent on the searched parameters of model $d_{b g}$, $\xi$ was presented on diagrams within the whole range of porosity changes. Its course allowed to find a procedure of calculating bubble velocity in the bed $u_{b}$ from Davidson Harrison relation:

$$
u_{b}=u_{0}-u_{m f}-u_{b r}
$$

or Kunii-Levenspiel relation for particles Geldart's group A according to:

$$
u_{b}=1.55\left[\left(u_{0}-u_{m f}\right)+14.1\left(d_{b g}+0.005\right)\right] d_{z}^{0.32}+u_{b r}
$$

and for Geldart's group B (Kunii and Levenspiel, 1991):

$$
u_{b}=1.6\left[\left(u_{0}-u_{m f}\right)+1.13 d_{b g}^{0.5}\right] d_{z}^{1.35}+u_{b r}
$$

where

$$
u_{b r}=0.711 \sqrt{g d_{b g}}
$$

From the matching experimental $\varepsilon_{f}=\mathrm{f}\left(u_{0}\right)$ and adapted procedure of calculation $u_{b}(8-11)$ bubble diameter $d_{b g}$ and voluminal ratio $\xi(12)$ were calculated, according to assumption Z5:

$$
\xi=\left(\frac{d_{b c}}{d_{b g}}\right)^{3}
$$

\section{RESULTS OF EXPERIMENTAL DATA ANALYSIS}

The diameter of bubbles calculated according to Kato-Wen model for the first experimental data source, for example in grain systems d1/SZ, d2/SZ, d3/SZ, is shown in Fig.2. 


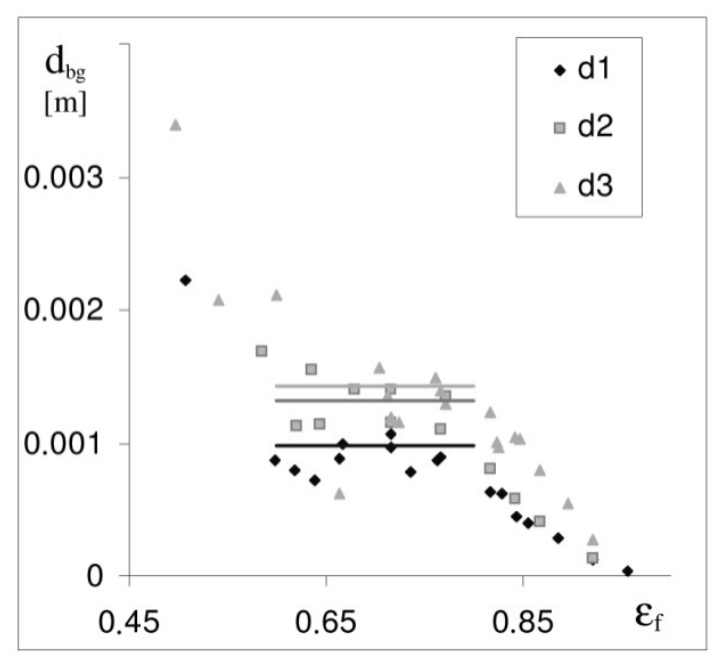

Fig. 2. Values of $d_{b g}$ in Kato-Wen model - systems $\mathrm{SZ} / \mathrm{d} 1-\mathrm{d} 3$

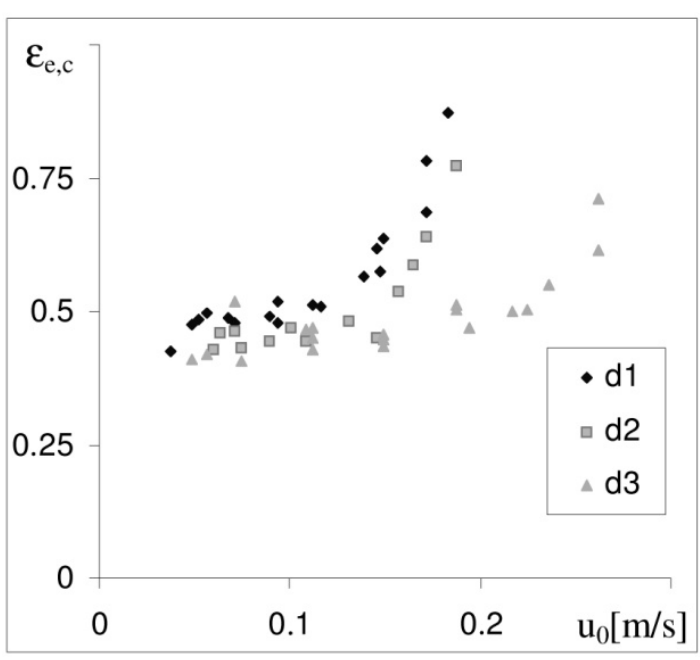

Fig. 3. Porosity $\varepsilon_{e}$ and $\varepsilon_{\mathrm{C}^{-}}$systems SZ/d1-d3

Characteristic changes for all the systems' ranges of bubble diameter $d_{b g}$ accompanying the layer porosity growth, were observed. Within $\varepsilon_{m f}<\varepsilon_{f}<0.58$ bubble diameters are reduced, beginning from a value similar to the diameter of channel between packed particles $\left(d_{z}=2.6 \cdot 10^{-3} \mathrm{~m} \mathrm{SZ}(13)\right)$. Within the range $0.58<\varepsilon_{f}<0.8$ value $d_{b g}$ is constant and similar to the diameter of spherical space between packed particles (in a tetrahedral system $1.76 \cdot 10^{-3} \mathrm{~m}$ and in a regular system $1.49 \cdot 10^{-3} \mathrm{~m}$ ). Within the range $0.8<\varepsilon_{f}<1$, bubble diameters are reduced to zero.

In case of the first two porosity ranges $\varepsilon_{m f}<\varepsilon_{f}<0.8$, bubble diameters depend on the geometry of packed bed inter-particle spaces, which confirms the origin of the assumptions Z1, Z5. As was mentioned before, departures from the rule in the vicinity of $\varepsilon_{m f}$ can result from interactions between bed-forming particles. A development and flow of bubbles bigger than $d_{z}$ (near $\varepsilon_{m f}$, in some bed areas) confirms occurrence of slugging. Possibility of its occurrence in confined fluidised bed was confirmed by some authors (Donsi et al., 1990; Michalski and Ziółkowski, 1999). An increase of $\varepsilon_{f}$ is accompanied by a decay of related stagnation zones, which favours bed unification and stabilisation of bubbles $\left(0.58<\varepsilon_{f}<0.8\right)$. The mean value of $d_{b g}$ within the range $\varepsilon_{m f}<\varepsilon_{f}<0.8$ increases with fluidised particles diameter increase and in the presented systems it amounts to: $1.1 \cdot 10^{-3} \mathrm{~m}, 1.3 \cdot 10^{-3} \mathrm{~m}, 1.4 \cdot 10^{-3} \mathrm{~m}$. Thus assuming $d_{b c}=1.49 \cdot 10^{-3} \mathrm{~m}$ according to Z5, voluminal ratio $r$ amounting in the presented systems to $2.4,1.52,1.05$ was calculated from relation (4). The values of $r$ are lower than those calculated from the conventional fluidisation Davidson Harrison relation. They decrease with the diameter increase of fluidised grains $(\mathrm{d} 1 \div \mathrm{d} 3)$. It probably results from the relocation necessity of bubbles surrounded with clouds and wakes within packed bed. The movement resistance restricts mainly the volume of clouds, whereas wakes follow bubbles in the upward movement. Thus a reduction of the ratio $r$ results from the solid body volume decrease in bubble wakes with the increasing fluidised particle diameters (analogy to conventional fluidisation (Rowe and Partridge, 1965, 1997)). Reduced particles flow within confined fluidised bed, as compared with conventional fluidisation, and its reduction with particle diameter increasing $\left(d_{f}\right)$ are indirectly confirmed by the results of examinations (Gabor, 1966; Roes and Van Swaaij, 1979).

Based on experimental $\varepsilon_{f}=\mathrm{f}\left(u_{0}\right)$ in the systems d1/SZ, d2/SZ, d3/SZ, including the assumed values of $d_{b g} \approx d_{b c}$, were converted into relation (3) obtaining porosities of emulsions, clouds and wakes (Fig.3). The calculated values are stable and close to $\varepsilon_{m f}$ for velocities corresponding to the first two porosity ranges $\varepsilon_{m f}<\varepsilon_{f}<0.8$ ). This directly confirms rightness of the assumption Z4 and indirectly of the assumption $\mathrm{Z} 3$ taken in the system analysis.

In case of the third porosity range, the assumptions $\mathrm{Z} 1 \div \mathrm{Z} 5$ are not satisfied. Probably (Fig. 2, 3) it is a case of slow porosity increase of the mentioned system phases as an effect of its structural 
destruction. The destruction occurs within range $\varepsilon_{f}$ where fluidised particles compose less than $8 \%$ of the bed volume.

If the ratio of inter-particle channel diameter to particle diameter in packed bed is expressed by

$$
\frac{d_{z}}{D_{p}}=\left(\frac{\varepsilon_{p}}{1-\varepsilon_{p}}\right)
$$

And the ratio of spherical maximal bubble volume to volume of packed bed grain is expressed by

$$
\frac{V_{b g x}}{V_{p}}=\left(\frac{d_{z}}{D_{p}}\right)^{3}
$$

the maximum volume fraction of bubbles in confined fluidised bed (referred to free space in packed bed) equals:

$$
\delta_{b g x}=\left(\frac{V_{z}}{V_{p}}\right)\left(\frac{V_{p}}{V_{t}}\right) \frac{1}{\varepsilon_{p}}
$$

substituting (13) and (14) to (15) can be expressed as:

$$
\delta_{b g x}=\left(\frac{\varepsilon_{p}}{1-\varepsilon_{p}}\right)^{3}\left(\frac{1-\varepsilon_{p}}{\varepsilon_{p}}\right)
$$

Its value, dependent on porosity $\varepsilon_{p}$ corresponds to porosity of confined fluidised bed:

$$
\varepsilon_{f x}=\left(\frac{\varepsilon_{p}}{1-\varepsilon_{p}}\right)^{2}\left(1-\varepsilon_{m f}\right)+\varepsilon_{m f}
$$

obtained from Eq. (16) and a relation used in bubbling-bed model (Eq. 5). System porosity exceeding value $\varepsilon_{f x}$ can result from dense phase porosity increase, as seen in Fig. 3. The experimental relation $\varepsilon_{f}=\mathrm{f}\left(u_{0}\right)$ and curve (Eq. 3) for Kato-Wen model (with assumptions Z1-Z5) are compared in Fig. 4. The curves were drawn using constant, previously calculated bubble diameters $d_{b g}$.

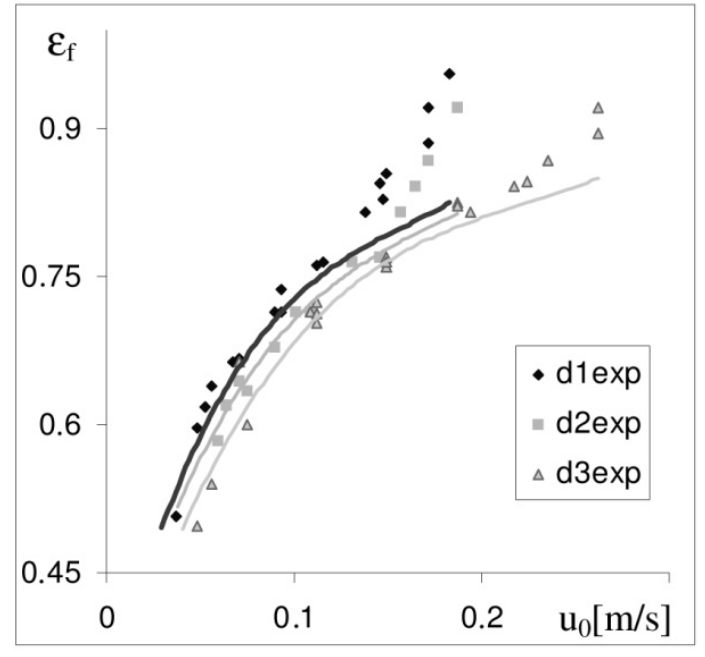

Fig. 4. Comparison of experimental $\varepsilon_{f}=\mathrm{f}\left(u_{0}\right)$ with Kato-Wen relation (3) for SZ/d1-d3

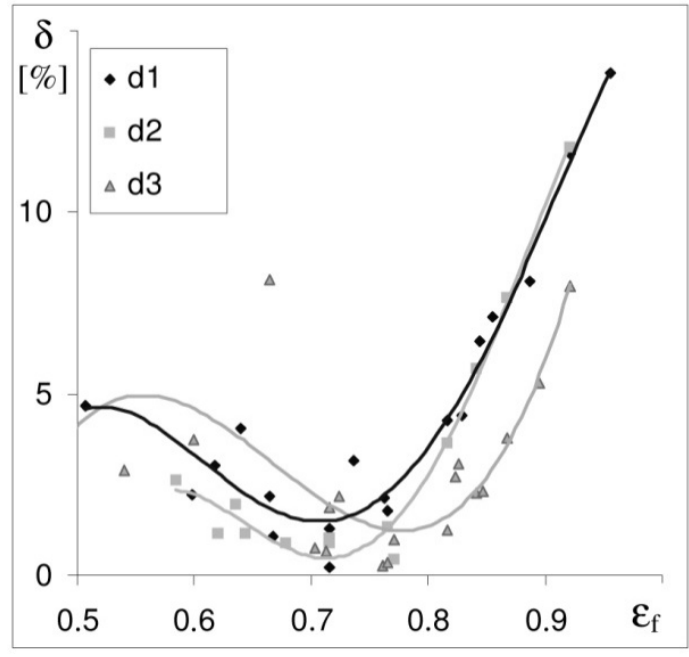

Fig. 5. Percentage error of matching Kato-Wen relation (3) - systems SZ/d1-d3 
Within the range $\varepsilon_{m f}<\varepsilon_{f}<0.8$ discrepancies are not bigger than $5 \%$ and they grow up to $15 \%$ for the porosity, where the model assumptions are not satisfied - see Fig. 5.

The experimental relation $\varepsilon_{f}=\mathrm{f}\left(u_{0}\right)$ within the systems $\mathrm{d} 1 / \mathrm{SZ}, \mathrm{d} 2 / \mathrm{SZ}, \mathrm{d} 3 / \mathrm{SZ}$ was also analysed according to Kunii-Levenspiel model. Value $a$ (Eq. 7) calculated (according to the procedure presented earlier) from experimental data, was compared with values $a$ obtained from bubble velocity $u_{b}$ (Eqs. 8 or 9, 10) and ratio $\xi$ (Eq. 12) - see Fig. 6. For particles Geldart's group A and B experimental data are better described by value $a$ calculated from the relations (Eqs. 7, 8, 12). This probably results from the fact that relations (Eqs. 9, 10) better describe the movement of bubble surrounded with other bubbles. However, in confined fluidised bed bubbles are isolated with packed particles. In Fig. 6, value $a$ obtained from relation (Eq. 3) divided by relation (Eq. 7) is also presented. The value was determined as an equivalent $a$ for Kato-Wen model, from experimental $\varepsilon_{f}=\mathrm{f}\left(u_{0}\right)$ and presented before $d_{b g}$. As seen from the comparison of curves $a=\mathrm{f}\left(\varepsilon_{f}\right)$ of both bubbling-bed models, smaller errors occur in KuniiLevenspiel model (particularly for higher porosities $\varepsilon_{f}$ ). This may result from the fact that gas flow in the emulsion was taken into consideration in the model.

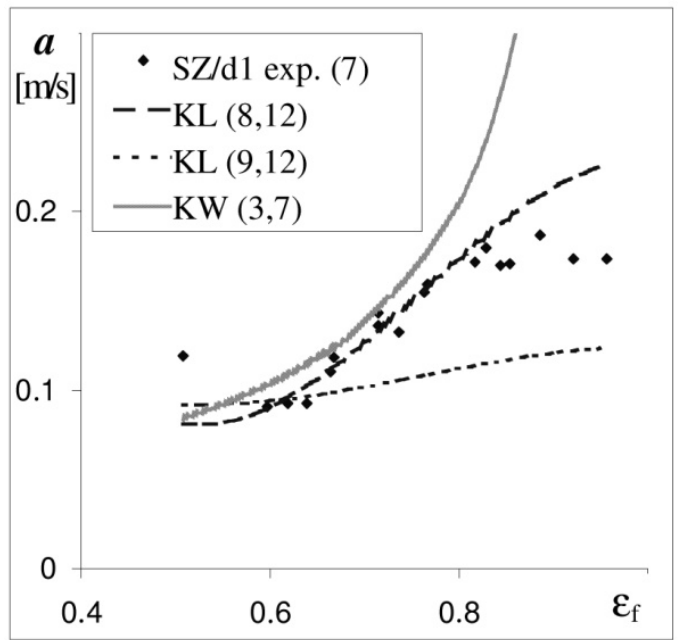

Fig. 6. Experimental $\boldsymbol{a}(7)$ and calculated from $\mathrm{u}_{\mathrm{b}}, \boldsymbol{\xi}$ : Kunii-Levenspiel $(8,12),(9,12)$ and Kato-Wen $(3,7)$

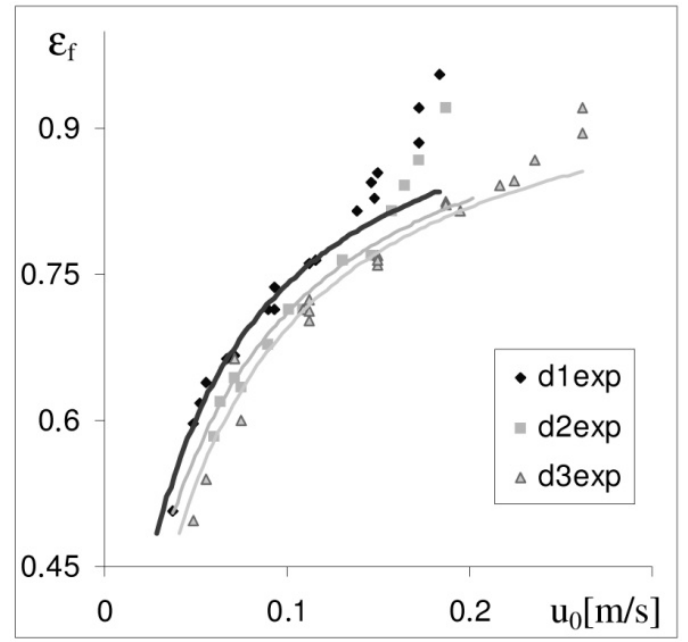

Fig. 7. Comparison of experimental $\varepsilon_{e}=f\left(u_{0}\right)$ with Kunii-Levenspiel relations for SZ/d1-d3

After substitution to Eq. (7) values (Eq. 8, 12), values $d_{b g}$ and $\xi$ were obtained from the matching (Fig. 7), according to Kunii-Levenspiel model. In systems SZ/d1-d3 the values amounted to: $2.2 \cdot 10^{-3} \mathrm{~m}$, $1.65 ; 2.4 \cdot 10^{-3} \mathrm{~m}, 1.2$ and $2.6 \cdot 10^{-3} \mathrm{~m}, 1.01$. Change tendencies are similar in both bubbling-bed models. However, in Kunii-Levenspiel model diameters $d_{b g}$ are higher and closer to the diameter of channels in packed bed $d_{z}$. Model curves (Fig. 7) for the above mentioned constant values $d_{b g}$, $\xi$, show good compatibility with the experiment within the range $\varepsilon_{m f}<\varepsilon_{f}<0.85$ with smaller error than in Kato-Wen model. Not illustrated experiments in beds TG, A4 also indicate a minor influence of the packed bed surface character onto the model parameters.

With respect to a similar scheme, experimental relations $\varepsilon_{f}=f\left(u_{0}\right)$ from the second data source (Donsi et al., 1990; Donsi et al., 1988) were studied. They concerned spherical particles in systems: d4 or d5 in one of three packed beds D1, D2 or D3. Fig. 8 illustrates values of gas bubble diameters $d_{b g}$ calculated from the Kato-Wen model in systems d4/D1 $\div$ D3 and d5/D1 $\div$ D3 .

As in the case of the first data source, three porosity ranges were observed: slugging occurrence $\left(\varepsilon_{m f}<\varepsilon_{f}<0.6\right)$, stabilization of diameters $d_{b g}\left(0.6<\varepsilon_{f}<0.85\right)$ and structural destruction $\left(0.85<\varepsilon_{f}<1\right)$. The lack of sharp boundaries between the ranges results from data representation by continuous Richardson-Zaki function. Previously observed (Fig. 2) tendencies of changing values $d_{b g}$ and $r$ with an increase of fluidised particles diameter $d_{f}$ were proved. For example, in systems d4/D1 and d5/D1 
they amount to: $0.9 \cdot 10^{-3} \mathrm{~m}, 2.65$ and $1.2 \cdot 10^{-3} \mathrm{~m}, 1.0$. In Fig. 8 we can additionally observe an influence of packed bed particles diameter change $D_{p}$. An increase of diameter $D_{p}$ results in an increase of bubble diameters $d_{b g}$ (for $\mathrm{d} 4 / \mathrm{D} 1, \mathrm{~d} 4 / \mathrm{D} 2$, d4/D3 they amount to: $0.9 \cdot 10^{-3} \mathrm{~m}, 1.4 \cdot 10^{-3} \mathrm{~m}, 1.8 \cdot 10^{-3} \mathrm{~m}$ ). It is consistent with problems discussed in the introduction to this study and assumption Z5. An increase of diameter $D_{p}$ results in increasing values of voluminal ratio $r$ (for d5/D1, d5/D2, d5/D3 amounting to: $1.0,1.6,1.65$ ). The last of the above mentioned values is similar to a value calculated (Kato and Wen, 1969) in conventional bed from Davidson Harrison relation. As can be suspected, an increase of the diameter $D_{p}$ is accompanied with a drop of bubbles surrounded with clouds and wakes movement resistance. In case of a suitably big packed particles diameter it can be similar to the movement in conventional fluidised bed. In Fig. 9 experimental values $\varepsilon_{f}=\mathrm{f}\left(u_{0}\right)$ were compared with relations (3) from Kato-Wen model and assumptions Z1-Z5 (for constants presented above $d_{b g}, r$ ). They indicate compatibility within the range $\varepsilon_{m f}<\varepsilon_{f}<0.85$ where the model's assumptions are satisfied. The systems in question $d 4 / D 1 \div D 3, d 5 / D 1 \div D 3$ were also exposed to the analysis consistent with Kunii-Levenspiel model and assumptions Z1-Z5. Satisfactory compatibility of experimental values with the model was reached for velocity $u_{b}$ calculated from relation (8) (movement of isolated bubbles).

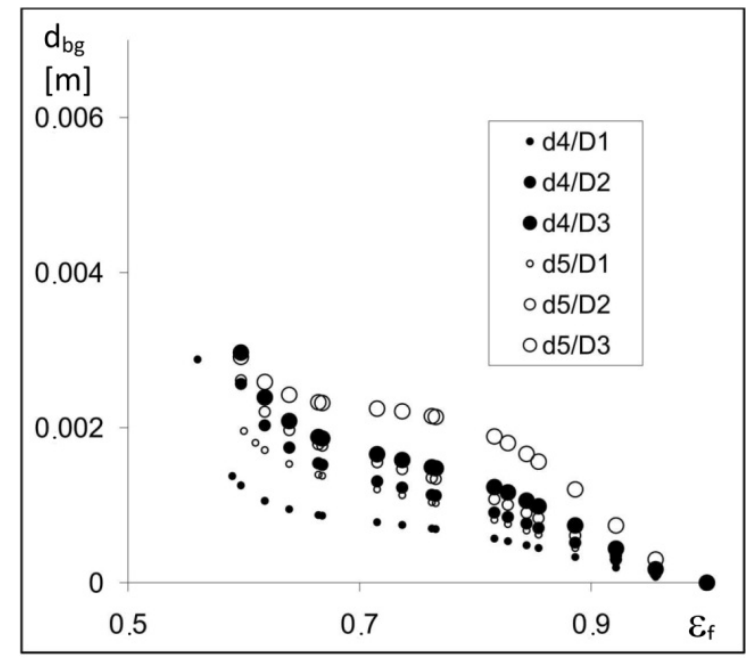

Fig. 8. Values of $d_{b g}$ of Kato-Wen model in systems: $d 4 / D 1-D 3, d 5 / D 1-D 3$

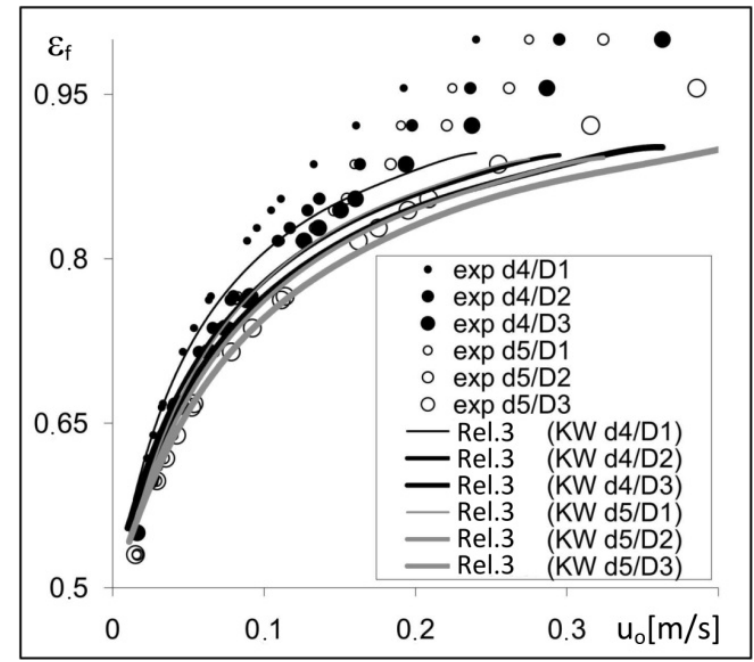

Fig. 9. Comparison of experimental $\varepsilon_{f}=\mathrm{f}\left(u_{0}\right)$ with Kato-Wen relations (3) in systems: d4/D1-D3, d5/ D1-D3

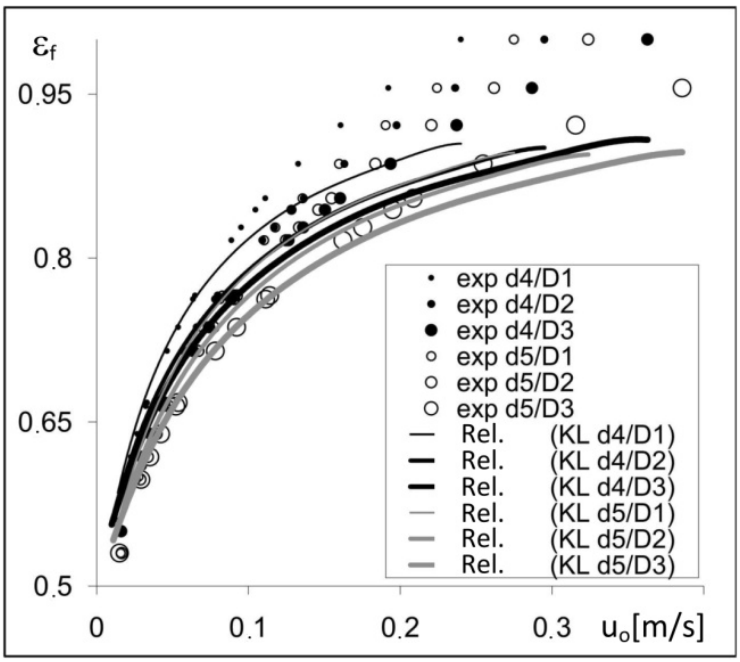

Fig. 10. Comparison of experimental $\varepsilon_{f}=f\left(u_{0}\right)$ with Kunii-Levenspiel relations in systems: d4/D1-D3, d5/ D1-D3

The values of $d_{b g}$ obtained from relations $(7,8,12)$ were slightly higher that those calculated from Kato-Wen model. However, changing tendencies of the model parameters $d_{b g}$, $\xi$ were analogous. 
Experimental values of presented systems were compared with model relations $(7,8,12)$, obtained for constant parameters $d_{b g}, \xi$ - see Fig. 10 . They proved compatibility with error not exceeding $5 \%$ within the range $\varepsilon_{m f}<\varepsilon_{f}<0.85$.

For the third source data analysis was conducted on the basis of experiments with open and closed confined fluidised bed (Michalski and Ziółkowski, 1999; Ziółkowski et al., 1989). Parameters of bubbling-bed models in systems of spherical particles $d 6 / D 4 \div D 6, d 6 \div d 8 / D 5$ were calculated from averaged values of both data sets. As compared with the systems presented before the applied particles diameters were bigger (in case of packed particles D4 $\div$ D6 with one order of magnitude).

According to the used scheme, bubble diameters $d_{b g}$ were studied using Kato-Wen model (with assumptions Z1-Z5), for increasing system porosity (Fig. 11). The division of the data, observed in previous data sources, into three porosity ranges is less distinct. However, $d_{b g}$ is slightly dependent on $\varepsilon_{f}$ within the porosity range $0.6<\varepsilon_{f}<0.85$ as compared with the range $0.85<\varepsilon_{f}<1$, where they decreased to zero (like in Fig. 2 and 8). The lack of growth of $d_{b g}$ above $d_{z}$ within the range $\varepsilon_{m f}<\varepsilon_{f}<0.6$ (typical for the previous data sources) results from slugging limited in open confined fluidised bed (Ziółkowski et al., 1989). Fig. 11 illustrates both components diameter influence analysis $\left(d_{f}, D_{p}\right)$ in the confined fluidised bed.

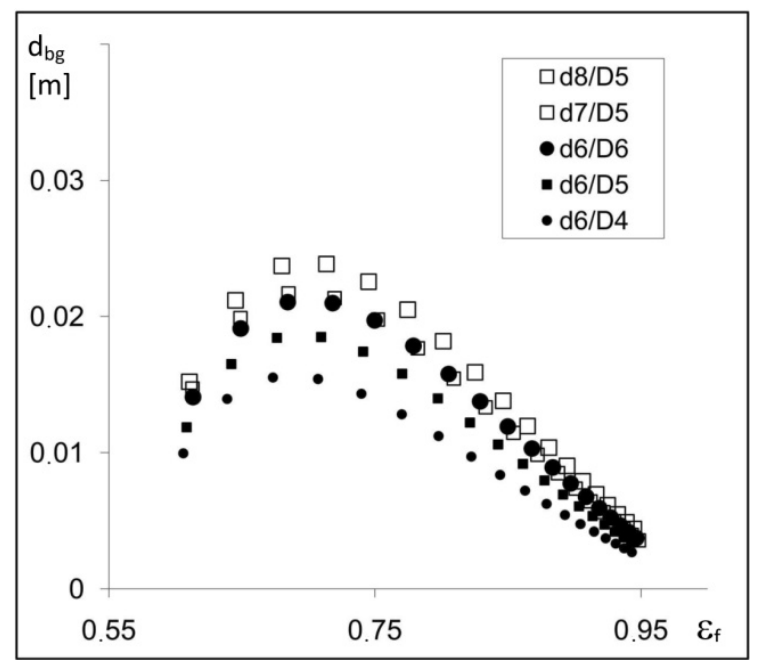

Fig. 11. Values of $d_{b g}$ of Kato-Wen model in systems: d6/D4 $\div \mathrm{D} 6, \mathrm{~d} 6 \div \mathrm{d} 8 / \mathrm{D} 5$

An increase of fluidised particles diameters $d 6 \div \mathrm{d} 8 / \mathrm{D} 5$ results in the increase of the bubble diameter up to the value $d_{z}$. For example, mean $d_{b g}$ value within the range $\varepsilon_{m f}<\varepsilon_{f}<0.85$ in systems d6/D5, $\mathrm{d} 8 / \mathrm{D} 5$ amounts to: $12.5 \cdot 10^{-3} \mathrm{~m}$ and $16.1 \cdot 10^{-3} \mathrm{~m}$ respectively. In systems $\mathrm{d} 6 / \mathrm{D} 4 \div \mathrm{D} 6$ where the diameter of packed grains raises, value $d_{b g}$ increased in a similar manner (d6/D4, d6/D6 $d_{b g}$ amount to $10.2 \cdot 10^{-3} \mathrm{~m}$ and $14.2 \cdot 10^{-3} \mathrm{~m}$ ). The observed bubble diameters $d_{b g}$ and values $r$ show trends of changes analogous to previously presented data sources. A comparison of experimental $\varepsilon_{f}$ with calculated values (3) in Kato-Wen model (Fig.12) confirms its application possibility in systems with large diameters of particles (small errors up to $\varepsilon_{f}<0.85$ and with a full range below 7\%).

Good compatibility with experimental values in the discussed systems was obtained also for relations of Kunii-Levenspiel model, for velocity $u_{b}$ calculated from relation (8). Changes of $d_{b g}$, $\xi$ with increasing diameter $d_{f}$ and $D_{p}$ were also similar to previously presented data sources. However, the matching error of the model curves (Eqs. 7, 8, 12) with experimental data was higher. However, it

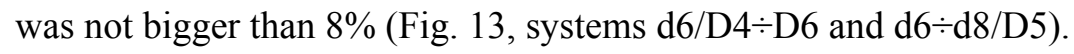




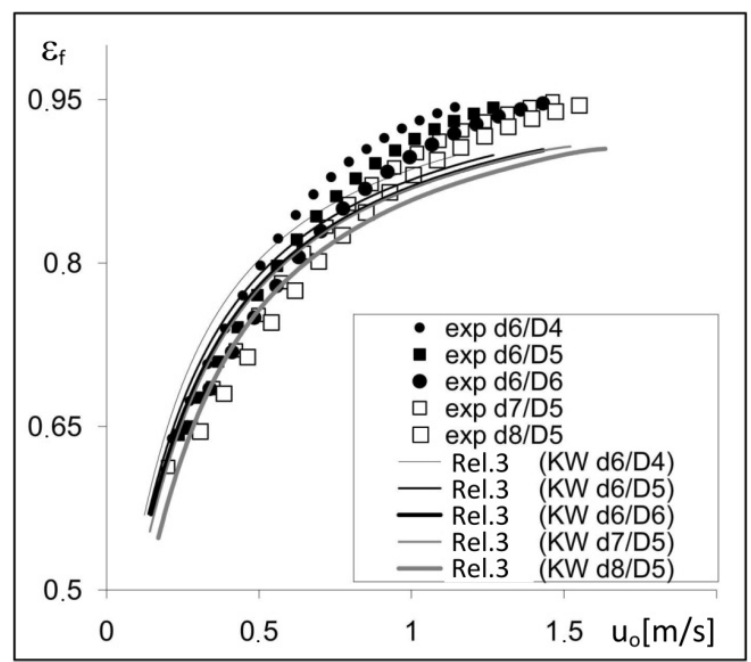

Fig. 12. Comparison of experimental $\varepsilon_{f}=\mathrm{f}\left(u_{0}\right)$ with Kato-Wen relations (3) in systems: d6/D4 $\div$ D6, d6 $\div$ d8/D5

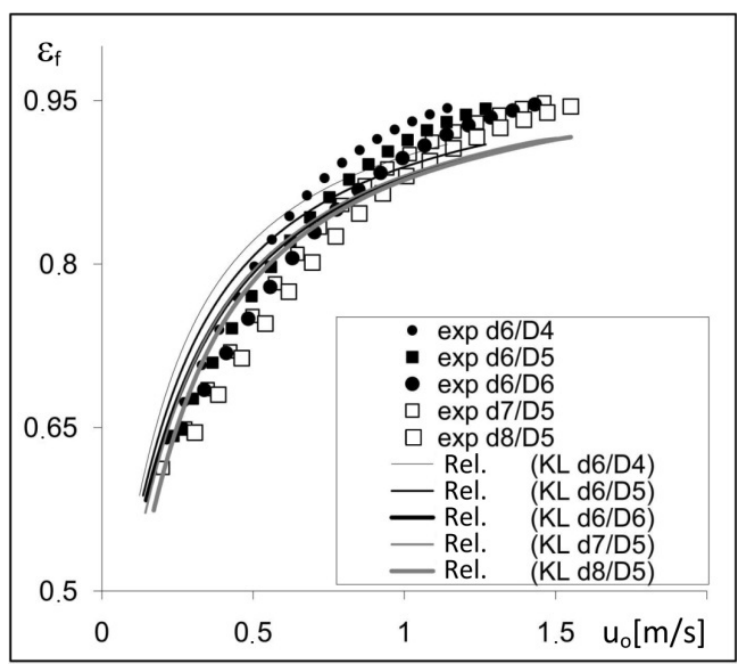

Fig. 13. Comparison of experimental $\varepsilon_{f}=\mathrm{f}\left(u_{0}\right)$ with Kunii-Levenspiel relations in systems: d6/D4 $\div$ D6, d6 $\div$ d8/D5

\section{SUMMARY AND CONCLUSIONS}

The examined models' parameters, calculated from characteristic assumptions Z1-Z5 to the bed, are gathered in Tab. 1.

Table 1. Parameters of bubbling-bed models in tested systems

\begin{tabular}{|c|c|c|c|c|c|c|c|c|}
\hline \multicolumn{3}{|c|}{ System/sign } & \multicolumn{2}{c|}{ diameter $d_{f}, D_{p}$} & \multicolumn{2}{c|}{ Kato Wen, Z1-Z5 } & \multicolumn{2}{c|}{ Kunii Leven., Z1-Z5 } \\
\hline fluid.par & pack.par. & $d_{z}\left[10^{-3} \mathrm{~m}\right]$ & $d_{f}\left[10^{-3} \mathrm{~m}\right]$ & $D_{p}\left[10^{-3} \mathrm{~m}\right]$ & $d_{b g}\left[10^{-3} \mathrm{~m}\right]$ & $r$ & $d_{b g}\left[10^{-3} \mathrm{~m}\right]$ & $\xi$ \\
\hline $\mathrm{d} 1$ & SZ & 2.6 & 0.055 & 3.6 & 1.1 & 2.40 & 2.2 & 1.65 \\
\hline $\mathrm{d} 2$ & SZ & 2.6 & 0.088 & 3.6 & 1.3 & 1.52 & 2.4 & 1.20 \\
\hline $\mathrm{d} 3$ & SZ & 2.6 & 0.125 & 3.6 & 1.4 & 1.05 & 2.6 & 1.01 \\
\hline $\mathrm{d} 4$ & D1 & 1.25 & 0.077 & 1.8 & 0.9 & 2.65 & 1.0 & 1.75 \\
\hline $\mathrm{d} 4$ & D2 & 2.0 & 0.077 & 3.0 & 1.4 & 2.70 & 1.6 & 2.00 \\
\hline $\mathrm{d} 4$ & D3 & 2.7 & 0.077 & 4.0 & 1.8 & 3.10 & 2.0 & 2.35 \\
\hline $\mathrm{d} 5$ & D1 & 1,25 & 0.108 & 1.8 & 1.2 & 1.00 & 1.3 & 0.90 \\
\hline $\mathrm{d} 5$ & D2 & 2.0 & 0.108 & 3.0 & 1.7 & 1.60 & 1.9 & 1.15 \\
\hline $\mathrm{d} 5$ & D3 & 2.7 & 0.108 & 4.0 & 2.2 & 1.65 & 2.5 & 1.20 \\
\hline $\mathrm{d} 6$ & D4 & 10.9 & 0.225 & 15.0 & 10.2 & 1.20 & 11.0 & 0.96 \\
\hline $\mathrm{d} 6$ & D5 & 16.4 & 0.225 & 20.0 & 12.5 & 2.30 & 15.0 & 1.30 \\
\hline $\mathrm{d} 6$ & D6 & 20.5 & 0.225 & 25.0 & 14.2 & 3.00 & 18.5 & 1.35 \\
\hline $\mathrm{d} 7$ & D5 & 16.4 & 0.275 & 20.0 & 14.0 & 1.50 & 16.5 & 1.00 \\
\hline $\mathrm{d} 8$ & D5 & 16.4 & 0.343 & 20.0 & 16.1 & 1.05 & 17.5 & 0.90 \\
\hline
\end{tabular}

The values in Tab. 1 were calculated as a mean value within the range $\varepsilon_{m f}<\varepsilon_{f}<0.85$, where compatibility with the model assumptions was proved. In Kunii-Levenspiel model $d_{b g}$ is higher than in Kato-Wen model (for small grains). This may result from taking into account gas flow in emulsion (in reflections on the model). In the presented data sets for both bubbling-bed models, bubble diameters are 
similar to the diameter of channels between packed particles. It confirms qualitative observations of other authors referring to the influence of packed bed onto gas bubbles size (Capes and Mcllhinney, 1968; Gabor, 1966). It refers systems examined in the present study where inter-particle spaces of packed bed are built of spherical particles. The limitation of space in which bubbles together with clouds and wakes are moved upward the bed also influences the value of voluminal ratio $r, \xi$. The values of $r, \xi$ are lower than the corresponding values of conventional fluidised bed. It is indirectly confirmed by phenomena typical for the confined fluidised bed: a reduction of the pressure drop along the layer height (Michalski and Ziółkowski, 1999), reduction of particles attrition (Gabor, 1966), a reduction of mass and heat exchange coefficients within the range $\varepsilon_{f}<0.7$ (Zabierowski, 2009; Zabierowski, 2008) as compared with conventional fluidised bed. Restraining of the slugging phenomenon was successful for high gas velocities within confined fluidised bed. The calculated bubble diameters are constant $\left(0.6<\varepsilon_{f}<0.85\right)$ and similar to $d_{z}$. However, according to the results of our examinations, slugging phenomenon occurs within a range close to $u_{m f}\left(\varepsilon_{m f}<\varepsilon_{f}<0.6\right)$ in closed confined fluidised bed. These conclusions are confirmed by results cited in article (Ziółkowski et al., 1989). However, the range of slugging is limited, which results from an insignificant growth of deformed bubbles, over $d_{z}$. Probably it results from re-distribution in higher layers of packed bed, which is in macro scale a homogeneous mixture of gas and fluidised particles. Differences in fluidisation character and changing tendencies of the examined model's parameters for A and B Geldart's group fluidised particles, as well as surface character and packed bed particles size within range $1.8 \div 25 \cdot 10^{-3} \mathrm{~m}$, were not proved. Bubble diameters in confined fluidised bed grow with increasing particles diameters of packed bed $D_{p}$ and fluidised phase $d_{f}$ up to $d_{z}$. Values of voluminal ratio $r, \xi$ grow in a reverse direction to $d_{b g}$ with a decrease of diameter $d_{f}$. For the same values $d_{f}$, an increase of packed bed particles diameter $D_{p}$ may result in bringing the particles closer to values typical for conventional fluidisation. The movement of bubbles (with clouds and wakes) is isolated through big particles of the confined fluidised bed. The results of the examinations proved that their velocity $u_{b}$ is similar to values calculated according to Davidson Harrison relation (8). Thus we can conclude that in this case, bed diameter slightly influences hydrodynamics of the system, which is proved in other examinations (Michalski and Ziółkowski, 1999). The quantitative aspect of the examined ratio $r, \xi$, supplemented with the analysis of mass and heat exchanges, will allow to use these models in design calculations.

According to all the data sources for $\varepsilon_{f}>0.85$, the assumptions of the bubbling-bed model are not satisfied. Bed porosity porosity grows faster than it was predicted by model curves (Figs. 4, 7, 9, 10, 12, 13), which as seen from Fig. 3 results from the unsatisfied assumption Z4. Value $\varepsilon_{f x}$ (Eq. 17), over which the system porosity and dense phase porosity increase together, for the examined systems amounts to: $0.78,0.74,0.82$ (respectively in three of the successive data sources). These values are close to porosities $\varepsilon_{f}$, over which discrepancies between bubbling-bed models curves compared with experimental porosities grown. The bed volume fraction of the fluidised grains (below 8\%), which is small in this range does not stabilise the system, where the bubbles fill up almost the whole space in solid packing. Growth of mass and heat exchange rate (Zabierowski, 2009; Zabierowski, 2008; Zabierowski, 2006) is observed within this range of the bed operation (in comparison to packed bed).

Finally we can conclude that:

- Kunii-Levenspiel and Kato-Wen models with assumptions Z1-Z5 can be applied for calculation of confined fluidised bed layer porosity. Discrepancies of $\varepsilon_{f}$ value, determined on the basis of the earlier mentioned bubbling-bed models do not exceed $8 \%$ of the error.

- The model parameters obtained from the matching of the model's relations to experimental data $\varepsilon_{f}=\mathrm{f}\left(u_{0}\right)$ allow to analyse fluidisation character as well as gas velocity regime and fluidised bed structural composition identification.

- A description of the regime of process in which confined fluidised bed is characterised with an increase of mass and heat transfer rate is also possible using the derived relation (17). 
The author is grateful for financial support of this work from projects No 11.11.210.244 (AGH).

\section{SYMBOLS}

a parameter in correlation (7), $\mathrm{m} / \mathrm{s}$

$d_{b g}, d_{b c} \quad$ diameter of a bubble, diameter of a bubble with cloud-wake, $\mathrm{m}$

$d_{f}, D_{p} \quad$ average diameter of fine particles, packed particles, $\mathrm{m}$

$d_{z} \quad$ diameter of channels between packed particles (Eq. 13), $\mathrm{m}$

$g \quad$ gravitational acceleration, $\mathrm{m} / \mathrm{s}^{2}$

$h_{m f} \quad$ fluidised bed height at $\mathrm{u}_{\mathrm{mf}}, \mathrm{m}$

$h_{z} \quad$ fluidised bed height at $\mathrm{u}_{0}, \mathrm{~m}$

$u_{0} \quad$ superficial gas velocity, $\mathrm{m} / \mathrm{s}$

$u_{b}, u_{b r} \quad$ bubble velocity in relation to column, to emulsion phase, $\mathrm{m} / \mathrm{s}$

$u_{f} \quad$ gas velocity in emulsion phase at $u_{m}, \mathrm{~m} / \mathrm{s}$

$u_{m b} \quad$ minimum bubbling velocity, $\mathrm{m} / \mathrm{s}$

$u_{m f} \quad$ minimum fluidisation velocity, $\mathrm{m} / \mathrm{s}$

$u_{s} \quad$ fines entrainment velocity, $\mathrm{m} / \mathrm{s}$

$V_{b g x} \quad$ maximum bubble volume, $\mathrm{m}^{3}$

$V_{p} \quad$ packed particle volume, $\mathrm{m}^{3}$

$V_{t} \quad$ packed bed volume, $\mathrm{m}^{3}$

Greek symbols

$\varepsilon_{f}, \varepsilon_{f x} \quad$ fluidised phase porosity, maximum porosity in bubbling-bed, $\mathrm{m}^{3} / \mathrm{m}^{3}$

$\vartheta \quad$ voluminal ratio of cloud-wake phase to bubble phase, $\mathrm{m}^{3} / \mathrm{m}^{3}$

$\delta, \delta_{x} \quad$ volume fraction of bubbles in a bed, maximum value in bubbling-bed, $\mathrm{m}^{3} / \mathrm{m}^{3}$

$\varepsilon_{b g}, \varepsilon_{e}, \varepsilon_{c} \quad$ porosity of bubble, emulsion, cloud-wake phase, $\mathrm{m}^{3} / \mathrm{m}^{3}$

$\varepsilon_{p} \quad$ packed bed porosity, $\mathrm{m}^{3} / \mathrm{m}^{3}$

$\rho_{f} \quad$ true density of fine particles, $\mathrm{kg} / \mathrm{m}^{3}$

$r, \xi \quad$ voluminal ratio of bubble and cloud-wake phases to bubble phase

in Kato-Wen model (Eq. 4), in Kunii-Levenspiel model (Eq. 12), $\mathrm{m}^{3} / \mathrm{m}^{3}$

\section{REFERENCES}

Baskakov A.P., Lummi A.P., 1963. Hydrodynamics of apparatus for drying materials in fluidized fine-grained pseudo-boiling bed with solid heat carrier. Khim. Prom., 11, $844-846$ (in Russian).

Buczek B., Geldart D., 1989. Effect of fine particles on properties of fluidised bed. Chem. Proc. Eng., 2, 313-329.

Buczek B., Zabierowski P., 2001. Removal of moisture by adsorption in confined fluidised bed. Chem. Proc. Eng., 4, 731-737.

Buczek B., Zabierowski P., 2003. Method for conducting adsorption process in solid bed with limited fluidisation. Polish Patent, PL202307.

Capes C.E., McIlhinney A.E., 1968. The pseudoparticulate expansion of screen-packed gas fluidised beds. AIChE J., 14, 917-922. DOI: 10.1002/aic.690140617.

Ciesielczyk W., 1992. Gas-solid mass transfer in a fluidised-bed drying. Chem. Proc. Eng., 4, 649-656.

Donsi G., Ferrari G., Formisani B., 1988. On the segregation mechanism of percolating fines in coarse particle fluidised beds. Powder Technol., 55, 153-158. DOI: 10.1016/0032-5910(88)80098-6.

Donsi G., Ferrari G., Formisani B., Longo G., 1990. Confined fluidisation of fine particles: Model and experimental description. Powder Technol., 61, 75-85. DOI: 10.1016/0032-5910(90)80068-A.

Dryden, H.L., Schubauer, G.B., 1947. Use of damping screens for reduction of wind tunnel turbulence. J. Aero. Sci., 14, 221-228. 
Gabor J. D., 1966. Fluidised-packed beds. Chem. Eng. Progr., Symp. Ser. 62, 62, 32-41.

Geldart D., 1973. Types of gas fluidisation. Powder Technol., 7, 285-292. DOI: 10.1016/0032-5910(73)80037-3.

Kato K., Wen C.Y., 1969. Bubble assemblage model for fluidised-bed catalytic reactors. Chem. Eng. Sci., 24, 1351-1369. DOI: 10.1016/0009-2509(69)85055-4.

Kunii D., Levenspiel O., 1991. Fluidisation Engineering, Butterworth-Heinemann, Boston, MA, USA.

Michalski J.A., Ziółkowski D., 1999. Aerodynamic characteristics of an organized fluidised system. Chem. Proc. Eng., 20, 89-108.

Roes A.W.M., Van Swaaij W.P.M., 1979. Hydrodynamic behaviour of a gas-solid counter-current packed column at trickle flow. Chem. Eng. J.., 17, 81-89. DOI: 10.1016/0300-9467(79)85001-7.

Rowe P.N., Partridge B.A., 1965. An x-ray study of bubbles in fluidised beds. Trans. Inst. Chem. Eng., 43, 157175.

Rowe P.N., Partridge B.A., 1997. An x-ray study of bubbles in fluidised beds. Chem. Eng. Res. Des., 75, Suplement, 116-134. DOI: 10.1016/S0263-8762(97)80009-3.

Sutherland I.P., Vassilatos G., Kubota H., Osberg G.L., 1963. The effect of packing on a fluidised bed. AIChE J., 9, 437-441. DOI: 10.1002/aic.690090406.

Wen-Ching Y., 2003. Handbook of Fluidisation and Fluid Particle Systems. China Particuology. DOI: 10.1016/S1672-2515(07)60126-2.

Zabierowski P., 2008. Heat transfer of the adsorption process in a confined fluidised bed. Chem. Proc. Eng., 29, 191-200.

Zabierowski P., 2009. Mass transfer in the adsorption process of water vapour in a confined fluidised bed. Chem. Proc. Eng., 30, 389-402.

Zabierowski P., 2006. Fluid and fine solid particles distributor for apparatus with confined fluidised bed. Polish Patent, PL208529.

Ziółkowski D., Michalski J., Hartman A., Svoboda K., 1989. Porosity of the fluidised phase generated by gas stream within the voids of the beds of spherical elements, and gas pressure drop in the system. Chem. Proc. Eng., 4, 603. 